\title{
Using science, technology and innovation in support of conserving Canada's ecosystems and habitats
}

\author{
by J. Cinq-Mars ${ }^{1}$ and E. Wiken ${ }^{2}$
}

Visions are strong drivers for developing science, technology and innovation. At a time when several signs are indicating a deteriorating global environment, developing a vision for conserving Canada's ecosystem services is timely. Instead of forecasting, backcasting is the approach recommended to facilitate the implementation of the conservation vision. It would include as one of its main components habitat conservation. Recommendations to achieve habitat conservation are provided. With a supporting policy framework, a conservation vision would be a strong incentive for developing science, technology and innovation.

Key words: vision, conservation, backcasting, habitat, science, technology, innovation

Une vision a souvent été un incitatif puissant pour le développement de la science, la technologie et l'innovation. Alors que des signaux nous indiquent une détérioration de l'environnement global, développer une vision pour la conservation des écosystèmes et des habitats canadiens est opportun. Au lieu d'opter pour la prévision pour implanter la vision, l'approche du backasting est préférable. Des recommandations pour réaliser la conservation des habitats sont présentées. Appuyée par un cadre politique approprié, une vision de la conservation serait un incitatif efficace pour le développement de la science, la technologie et l'innovation.

Mots clés: vision, conservation, backcasting, habitat, science, technologie, innovation

"Innovation is creative destruction"

J.A. Schumpeter

\section{Introduction}

From the tools of the hunters and gatherers and those of the first farmers to the sophisticated technologies pervasive in today's world, it is easy to recognize the importance of innovation, science and technology in allowing society to gradually extract numerous benefits from its environment and improve its standard of living. The pursuit of better living conditions has been a strong driver for the innovation, science and technology triad and has allowed an exponential growth in global population. However, how has this trial worked for the benefit of conserving ecosystems and habitats?

Up to the mid-1900s, progress in society's living conditions has occurred without major environmental disruptions. However, various indicators signal that human population and development are having significant impacts on the ecosystems of the planet; environmental, social and economic assets have all been affected to varying degrees. Often, these effects have been interlinked. The natural carbon cycle is affected by $\mathrm{CO}_{2}$ emissions; the nitrogen cycle is an increasing concern among scientists; the number of endangered habitats, ecosystems and species is increasing; desertification and deforestation expand in many countries. The current scientific and technological discoveries that have permitted improved living conditions for the past 10000 years are now causing perverse effects on the life-support systems of the planet that are essential for wildlife as well as people. In Canada, several ecoregions have seen their productivity decline due to acidic precipitations; the

${ }^{1}$ Executive Director, Wildlife Habitat Canada/ Habitat Faunique Canada, 7 Hinton Ave. N., Suite 200, Ottawa, Ontario K1Y 4P1. E-mail: jcinqmars@whc.org

${ }^{2}$ Wildlife Habitat Canada, 7 Hinton Ave. N., Ottawa, Ontario K1Y 4P1

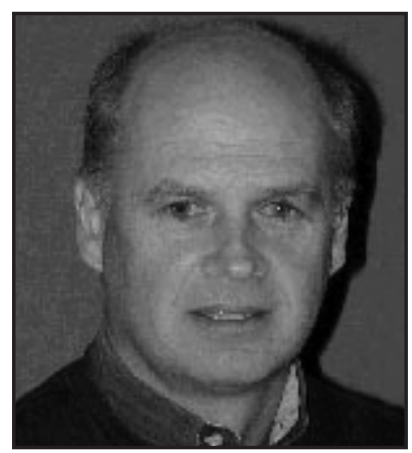

J. Cinq-Mars

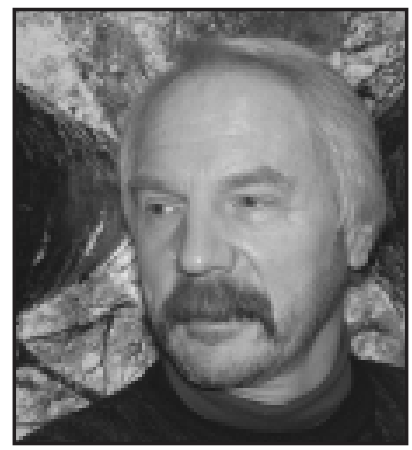

E. Wiken
Arctic is already showing the strains of climate change and agricultural and urban sprawl practices have taken a toll on our country's most unique and productive habitats (WHC 2001). Obviously, current policies and programs to ensure the conservation of earth's life-support systems are not adapted to the environmental threats challenging our society and its lifestyle environmental goals and economic objectives.

Since science, technology and innovation have been fundamental in improving our standard of living, it is obvious that some of the solutions to the current environmental problems that we are facing today will have to come from them.

\section{Stimulating Science, Technology and Innovation}

Sending adequate signals to the market or the economy has proven to be one the most effective ways of imparting changes in the behaviour of decision-makers and consumers (OECD 1997). The proverbial challenge for man to reach the moon by the end of the 1960s launched by President Kennedy in the early years of that decade has been instrumental in channelling innumerable energies and innovations in science, technology, 
management and finance to reach this goal. His vision inspired a whole society even after his own death.

Visions take the common understanding of ideas' desirability and feasibility, and project them into the not-too-distant future. These visions are flexible, dynamic and exert great influence on the direction of science, technology and innovation processes. For the OECD, visions of technological developments serve three-fold functions by: (1) providing orientation, (2) facilitating co-ordination, and (3) stimulating motivation. In their orientation function, they provide a reference point to which individuals can focus their perceptions, thoughts, and decisionmaking processes in a way that effectively establish common thoughts on the future. Visions work in their coordinating role to establish a basic understanding among individuals and organizations. The existence of this common ground is especially significant in providing a platform where experts and laypersons can meet, overcoming what are often vastly different frames of references and significantly simplifying the required co-operation between these two groups. Visions serve a motivational function in that ideas or perceptions are present in both the minds and hearts of individuals (OECD 1997).

To address and resolve the range of environmental and socio-economic issues of today, we have to go back to the fundamentals and try to identify what we really want. Defining what environmental objectives are required allow for a definition of a conservation vision that would tell us how Canada's natural resources should be managed and how Canada's land and water-based habitats and landscapes should be protected. The vision would have to be achieved over a period of time considerate of the realities of the environment, the economy and society at the ecosystem and environmental values.

\section{Implementing the Vision with Backcasting}

Once a vision is defined, backcasting can be used to plan the steps necessary to achieve it. Backasting is a relatively uncommon approach in the decision-making sphere and can be considered as the mirror image of forecasting. Most futures studies relating to the environment have been forecasts, based on the reverse approach. They begin by forecasting what will happen if current trends are allowed to continue un-hindered. Then, based on the scenario that emerges, they go on to recommend action to steer those trends in the right direction (OECD 1999).

However, prediction is an uncertain business. For example, in February 2001, 95\% of American economists polled said that recession would not happen but the National Bureau of Economic Research (NBER) declared in December of the same year that the recession began in March of the same year (The Economist, Dec. 1, 2001). Extrapolations about the environment, a much more complex system, are even more challenging and those that have attempted to do so, such as the Club of Rome, have often erred. Relying on the market system and on the efficient allocation of resources is tempting but correcting the imperfections of the market is a never-ending task and a reactive approach. Perhaps it is safer to define what we want and map corridors of likely development based on a variety of scenarios to achieve the desired goals.

The advantage of backcasting over forecasting is that it makes the need for change clearly visible and exposes goal conflicts. It enables us to think creatively about the society of tomorrow, without being blinded by the obstacles and problems that exist just at the moment.
Forecast probable events $\leftarrow---$ future $---\rightarrow$ Backcast from desired events

It is a powerful planning tool that serves to identify the various elements (i.e., objectives, institutions, instruments, behavioural changes) necessary to achieve the vision. Backcasting should include a description of the path from the current situation to the desired one.

\section{A Conservation Vision For Canada's Ecosystems and Habitats}

Assuming that visions are grounded on solid principles and not on the buzzwords of the day, they can be persuasive and effective. However, defining for Canada a vision of conservation for a period of time adequate for implementing institutional, social and economic changes would most likely require more than 25 years. Such a period of time would allow for the introduction of gradual measures more easily accepted by the market than drastic measures required when the urgency of the situation has become fully apparent. Moreover, short-term environmental policies tend to foster minor technical improvements instead of clean and integrated technologies (Hemmelskamp and Hohmeyer 1998). One could consider the time to implement the visions of setting aside $12 \%$ of the land and water as conservation areas or restoring certain populations of fish at commercial harvest levels. Whereas these are good visions on their own, they can only contribute partially to the conservation challenges posed by the imbalance of the carbon and the nitrogen cycles, the continued stress imposed by climate change, cumulative impacts of various toxic chemicals, habitat fragmentation, an increasing world population and its demand for additional resources.

Conserving and restoring the ecological functions, structures and services of Canada's ecosystems could be the basis of a broader conservation vision for the next 25 years. The tasks are complicated but so, too, are the issues. Conserving and restoring forests, species, water quality, and soil resources on their own will not do. The realities of resource management and known linkages and interdependencies have clearly shown that independent and non-systems-based actions will fail. For the first decade of this century, the OECD (2001) in its environmental strategy adopted by Environment ministers in May recommended "maintaining the integrity of ecosystems through efficient management for natural resources." The integrity of ecosystems will be preserved by the detoxification of substances released to the environment, decarbonization of energy, conservation of biological diversity and sustainable use of natural resources. The broader vision for 25 years builds on the OECD goal but adds the need for restoring ecological functions, structures and processes.

Ecosystems provide a range of essential goods and services in the environmental and human context: economic (fish, pulp and game) and social (traditional, cultural and recreational activities) services.

Some of the essential ecological functions are the following:

- Trees and plants clean the atmosphere by acting as filters of pollutants.

- Marshes trap sediments and wastes and serve to moderate flooding.

- Plants produce oxygen through photosynthesis.

- Habitats support biological diversity.

- Oceans and forests act as carbon sinks. 
Most likely, achieving this vision would rely on a combination of various policies and tools. They can be grouped in four categories (Margouluis and Salafsky 2001):

1. Direct Protection

2. Policy Development and Advocacy

3. Education and Awareness

4. Changing Incentives

To which it would be reasonable to add a fifth category:

5. Monitoring and Reporting

The last category would ensure that progress is measured to verify the effectiveness of policies and tools. Monitoring and reporting provide a continual feedback to stakeholders. Corrective actions could be taken if necessary.

Changing incentives may prove to be the most challenging category because there is currently no method for evaluating a balance of complementary goals as the majority of decisions are still made on the basis of social, economic and political forces. Therefore, developing an analytical and institutional framework for resolving these complementary goals will be necessary. As well, ways of communicating to decision-makers and the broad public and synthesizing information about the value of ecosystems and their services that support the economy will be needed.

\section{Canada's Challenge with Habitat Conservation}

Habitat conservation is one of the essential pillars of ecosystem conservation. In fact, it is the "substrate" that supports many of the ecosystems goods and services. Although Canada's habitats are the envy of the world, they are facing several issues that will require changes in governance:

1. Multiplicity of management approaches

- Ten provincial, three territorial, and one federal government share the management of habitats in Canada. Each one has great autonomy in developing habitat programs. As well, there are significant linkages with neighbouring countries and states.

- Habitat conservation programs are based on political limits with few relationships with ecosystems, landscapes and seascapes.

- A lack of a co-ordinated approach makes it difficult to address issues affecting our landscapes/seascapes that often span several jurisdictions.

2. Regional- and species-focussed approaches

- Habitat conservation, in most cases, is based on local ecosystems or local species. It is mostly centred on the requirements of a single species or on the need to mitigate habitat changes from development.

- Species and regional approaches are inadequate with largescale issues such as urban growth, habitat fragmentation, climate change, invasion by non-native species, etc.

3. Site-specific management

- Habitat conservation is mostly practised in formal conservation areas. Unfortunately, they frequently combine functions that are not totally compatible with habitat conservation.

- Inadequate buffer zones or ecosystem management plans around conservation areas reduces their habitat values

4. Incomplete habitat information

- Information available to assess habitats in all landscape and seascapes is in most cases absent, patchy or of limited relevance
5. Monitoring systems, indicators and reporting systems

- The absence of monitoring, indicators and reporting systems perpetuate a "react and cure" approach to habitat management and prevents an adequate assessment of current conservation or resource management policies for long-term planning.

6. International responsibilities

- The migratory nature of several of our species and their habitat needs requires strong co-operation with other countries. Existing programs with Russia, Greenland, the US and Mexico and others have to be expanded and include other countries.

7. Resources

- The current level of resources to address habitat conservation is not appropriate to protect threatened habitats or endangered species and to effectively plan how we could prevent further damage of Canada's habitats and the biodiversity they contain.

In its report on the Status of Wildlife Habitats, Wildlife Habitat Canada (2001) recommends the following actions to steer habitat conservation in the direction of ecosystem conservation:

1. Create a national council on habitat.

2. Develop wildlife habitat objectives and indicators.

3. Establish a habitat monitoring and reporting system.

4. Develop a habitat sustainability index.

5. Estimate habitat conservation trends for each major landscape and seascape.

6. Improve communications on the issue of habitat conservation.

7. Evaluate the habitat values of conservation areas.

8. Establish conservation areas around urban areas.

9. Extend stewardship to the Arctic and urban landscapes and oceanic and coastal seascapes.

10. Review the current policy framework of land, water and natural resource uses to correct perverse effects on habitats.

11. Assess the impacts of non-point source pollution on habitats.

12. Improve the allocation of resources for conservation agencies to address habitat conservation.

\section{Science, Technology and Innovation-Their Impacts}

The development of science, technology and innovation may commonly be viewed as being against the interests of conservation. They are more typically seen as the agents speeding up the means and extent of resource exploitation and harvesting. However, how can they be more complementary to a conservation vision? They need to be flexible and dynamic so as to exert great influences on the direction of the innovation processes. Most often, they will do so as a result of the interaction of technological, institutional and organizational changes (Dierkes et al. 1996). As we have witnessed in the past, science, technology and innovation have made considerable positive impacts on the reduction of stress factors. We can expect additional positive contributions, especially for conservation ends, provided that the right policy framework is in place to encourage innovation, scientific and technological developments including market conditions. Identifying specific ones is uncertain because the origin of ecosystems and habitat threats is both direct and indirect.

However, for direct threats, we can expect progress in the fields of: 
- Agricultural, fishery and forestry practices,

- Mining, oil and gas exploration and exploitation,

- Biotechnology and genetic engineering,

- Remote sensing,

- Eco-efficiency,

- Pollutants reduction,

- Energy efficiency,

- Transport,

- Habitat restoration,

- Land-use planning.

Benefits from science, technology and innovation can be great but they also present potential negative effects. Contaminating wild species with GMOs is a real threat, as is the use of various pesticides. Scientific research will be required to alleviate some of these problems and prevent significant damage to the ecosystems and habitats. Science, technology and innovation also have heir own limitations. A study completed by the OECD (1997) estimated the potential contribution of science and technology at 50\% to achieve environmentally sustainable transport, the balance having to come from behavioural changes.

Finally, unless consumption patterns from an increasing population are directed toward improved efficiency in material and energy, reduced wastes, cleaner production and pollution prevention, conserving ecosystems and habitats will remain a difficult challenge.

\section{Conclusions}

Science, technology and innovation have all made significant contributions to society and less so to the conservation of ecosystems and habitats. Their contributions are becoming more important today as we are getting several indications that human populations and development are affecting the life-support systems of our planet. These systems support people as well as wildlife.

Identifying a vision of ecosystem conservation, including habitat, would be a strong incentive for science, technology and inno- vation. By sending clear signals to society, visions have proven to be very effective in providing new orientations, facilitating co-ordination and stimulating motivation. Using backcasting as a means of achieving a vision can further improve its effectiveness.

To remain robust and inspiring, a conservation vision would have to span a period of time of approximately 25 years and would need to be grounded on the conservation and restoration of ecological functions, structures and services of Canada's ecosystems. It would include habitat conservation as one of its main pillars. However, to achieve habitat conservation in Canada, several institutional changes are required. The report by Wildlife Habitat Canada (2001) submits several recommendations. One of the key recommendations is the creation of a Wildlife Habitat Council to provide a forum to address habitat issues from an ecosystem approach. Implementing these recommendations would stimulate science, technology and innovation in many fields, including governance.

\section{References}

Dierkes, M., U. Hoffman and L. Maz. 1996. Visions of technology; social and institutional factors shaping the development of new technologies. St-Martins, New-York.

Hemmelskamp, J. and O. Hohmeyer. 1998. IPTS report.

Margoluis, R. and N. Salafsky. 2001. Is our project succeeding? A Guide to Threat Reduction Assessment for conservation, Washington, D.C.: Biodiversity Support Program

OECD. 1997. Environmentally Sustainable Transport: Synthesis Report on Phase 2 of the EST Project, Env/EPOC/PPC/ Final, Paris.

OECD. 1997. General Secretariat on multidisciplinary issues. Paris. OECD. 1999. Indicators for the Integration of Environmental Concerns into Transport Policies. Env/EPOC/SE (98) 1 Final, Paris. OECD. 2001. Environmental Outlook Paris.

Wildlife Habitat Canada (WHC). 2001. The Status of Wildlife Habitats in Canada. Ottawa. 